\title{
Contação de Histórias e Educação Etnicorracial: um Convite a Mulheres Negras
}

\author{
AGUIRRE, Kathleen Kate Dominguez ${ }^{1}$ \\ $P A I X \tilde{A} O$, Cassiane de Freitas $^{2}$
}

\section{RESUMO}

Neste trabalho temos por objetivo analisar representações excludentes reproduzidas nos espaços escolares, a partir das categorias raça, pobreza, perspectivas de mundo e futuro, relacionando narrativas autobiográficas de três mulheres negras aos dados coletados em agosto de 2016, durante encontros de contação de histórias de temática afro-brasileira com crianças da Escola Alcides Barcelos, no Bairro Getúlio Vargas, retrato da exclusão social e racial da cidade do Rio Grande/RS. Baseamo-nos em debates teóricos sobre exclusão, processos de representação social e educação etnicorracial, para então realizar a investigação no espaço escolar. Concluímos que não é suficiente acreditar numa transformação social através da Escola, visto que ela serve a ordem dominante e reproduz representações sociais e raciais excludentes com vistas à sua manutenção. Contudo, acreditamos que é possível que os agentes sociais produzam uma reeducação das relações etnicorraciais através de experiências no cotidiano escolar e do ensino de História.

Mulheres negras. Educação Enticorracial. Escola.

\section{Storytelling and Ethnic-Racial Education: an Invitation to Black Women}

\begin{abstract}
In this paper we aim to identify exclusionary representations reproduced in the school space, from the subjects of race, poverty, perspectives of the world and future, relating autobiographical narratives of three black women to data collected in august 2016, during african-brazilian storytelling meetings with children at the Alcides Barcelos School in the Getúlio Vargas Neighborhood, portrait of the social and racial exclusion of the city of Rio Grande/RS. We are based on the theory discussion about exclusion, processes of social representation and ethno-racial

\footnotetext{
${ }^{1}$ Doutoranda em Ciências Sociais Universidade do Vale do Rio dos Sinos (UNISINOS). E-mail: katedominguezaguirre@gmail.com. Lattes: http://lattes.cnpq.br/1186284529513203 Orcid: https://orcid.org/0000-0002-0086-1789.

${ }^{2}$ Doutora em Educação (UNISINOS). Professora Associada Universidade Federal do Rio Grande (FURG). E-mail: cassianepaixao@outlook.com. Lattes:

http://lattes.cnpq.br/9836646117494150. Orcid: https://orcid.org/0000-0002-8085-1862.
} 
education, in order to carry out practical research in the school space. We conclude that it is not enough to believe in a social transformation through the school, since it serves the dominant order and reproduces social and racial representations with a view to its maintenance. However, we believe that it is possible for social agents to produce a re-education of ethno-racial relations through experiences of daily school life and teaching History.

\section{Black Women. Ethnico-racial Education. School.}

\section{Narración de historias y educación etnicorracial: una invitación a las mujeres negras}

\section{RESUMEN}

En este trabajo pretendemos analizar las representaciones excluyentes reproducidas en los espacios escolares, desde las categorías raza, pobreza, perspectivas del mundo y el futuro, relacionando las narrativas autobiográficas de tres mujeres negras con los datos recogidos en agosto de 2016, durante los encuentros de narración de historias con temática afrobrasileña con niños de la escuela Alcides Barcelos, en el barrio Getúlio Vargas, un retrato de la exclusión social y racial en la ciudad de Rio Grande / RS. Nos basamos en debates teóricos sobre exclusión, procesos de representación social y educación etno-racial, para luego realizar la investigación en el espacio escolar. Concluimos que no basta creer en una transformación social a través de la Escuela, ya que ésta sirve al orden dominante y reproduce representaciones sociales y raciales excluyentes produciendo su mantenimiento. Sin embargo, creemos que es posible que los agentes sociales produzcan una reeducación de las relaciones étnico-raciales a través de experiencias en la rutina escolar y en la enseñanza de Historia.

\section{Mujeres Negras. Educación Enticorracial. Escuela.}

\section{Raconto e educazione etnico-razziale: un invito per le donne di colore}

\section{SOMMARIO}

In questo lavoro si intende analizzare le rappresentazioni esclusive riprodotte negli spazi scolastici, dalle categorie di razza, povertà, prospettive del mondo e futuro, mettendo in relazione le narrazioni autobiografiche di tre donne nere con i dati raccolti nell'agosto 2016, durante gli incontri Narrazione a tema afrobrasiliano con i bambini della scuola Alcides Barcelos, nel quartiere di Getúlio Vargas, un ritratto dell'esclusione sociale e razziale nella città di Rio Grande / RS. Ci siamo basati su dibattiti teorici sull'esclusione, sui processi di rappresentanza sociale e sull'educazione etnico-razziale, per poi svolgere la ricerca nello spazio scolastico. Concludiamo che non basta credere in una trasformazione sociale attraverso la Scuola, poiché essa serve l'ordine dominante e riproduce rappresentazioni sociali e razziali esclusive, producendone il mantenimento. Tuttavia, crediamo che sia possibile che gli agenti sociali producano una

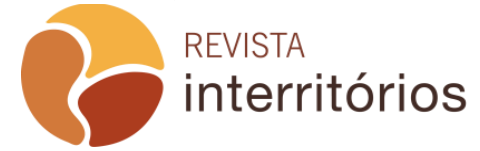


rieducazione delle relazioni etnico-razziali attraverso esperienze nella routine scolastica e nell'insegnamento della Storia.

Donne nere. Educazione etnico-razziale. Scuola.

\section{INTRODUÇÃO}

A contação de histórias pode tornar possível a introdução da História Africana e Afro-Brasileira nos anos iniciais do ensino fundamental e proporcionar uma reeducação etnicorracial (SOUZA, 2012, p.19) e a promoção de representações positivas (ZIVIANI, 2012). Os contos de temática afro-brasileira e africana e o protagonismo de negros e negras nos espaços de ensino podem influenciar as perspectivas de História, de mundo e futuro de crianças em idade escolar, rompendo com a reprodução de representações estigmatizadas e inferiorizantes das crianças negras e desenvolvendo afeto, autoestima e posturas antirracistas no espaço escolar (AGUIRRE, 2017).

Acreditamos, contudo, que continuam se "produzindo e re-produzindo" representações baseadas nas versões dos dominadores/exploradores coloniais, transpostas para um grupo considerado excluído e que não se vê representado na História, como ela é contada e por quem ela é contada. Isto acontece no ensino básico, o ensino de História é utilizado como instrumento de manutenção de poderio, perpetuando as exclusões social e racial e os estereótipos intrínsecos às mesmas.

A partir das discussões de Bourdieu (2012), Munanga (2005) e Chartier (2004) entendemos que as estruturas sociais dominantes têm como instrumento de reprodução as representações que permeiam as práticas e discursos de agentes e grupos sociais. A partir destas bases teóricas compreendemos que representações sobre raça e classe são reproduzidas e socializadas nas relações sociais de forma negativa e marginalizada, como estratégia de manter a exclusão racial no Brasil, privilegiando simbólica e materialmente os grupos dominantes não-pobres e não-negros. Desta forma, estas representações são incorporadas pelos atores pobres e negros, condicionando o habitus destes grupos e, consequentemente, suas perspectivas de si, de mundo e de futuro.

Entretanto, entendemos que os grupos excluídos constroem saber histórico. Assim, lançamos mão das discussões de Chartier que, em diálogo com Bourdieu (BOURDIEU; CHARTIER, 2011), diz que embora as representações excludentes (e racistas, acrescentamos) sejam dominantes e naturalizadas, a partir do momento que são produzidas historicamente por conflitos e relações de poder, elas podem também ser modificadas.

Para Ziviani (2012), mulher negra, professora e alfabetizadora, a construção da identidade étnica se dá no conflito de diferenças entre si e o outro, ou seja, no convívio social. A fala, também é construída socialmente e, assim, 
as contradições e conflitos de raça e classe estão expostos e representados na mesma. Segundo Ziviani "no contexto dessa socialização a criança se percebe e se identifica como sendo parte de um determinado grupo social" (2012, p.54).

A partir destas premissas teóricas e tendo por objetivo identificar as representações de raça e pobreza, bem como as perspectivas de mundo e futuro de crianças, propusemos uma prática investigativa através da contação de histórias de temática afro-brasileiras mediada por mulheres negras engajadas na construção de uma educação etnicorracial. Identificamos, assim, nestas práticas a possibilidade de trabalharmos uma forma de romper com a história e ensino tradicional das escolas que reproduzem representações excludentes, produzindo visões de mundo que contemplem a identidade e igualdade racial de crianças negras (SILVA, 2007) e desconstruam privilégios da branquitude (CARDOSO,2010; PINHEIRO,2014; SCHUCMAN,2016).

Desta forma, foram propostos encontros semanais com crianças de $4^{\circ} \mathrm{e}$ 5 ano da Escola Estadual de Ensino Fundamental Alcides Barcelos, no Bairro Getúlio Vargas, retrato da exclusão sócio-racial da cidade do Rio Grande/RS. Nestes encontros, três mulheres negras ficaram responsáveis pela contação de histórias de temática afro-brasileira e conversação com as crianças. Os encontros foram gravados em áudio e vídeo e registrados em diários de campo, de forma descritiva, para que posteriormente pudéssemos identificar (ou não) nas falas das crianças categorias de análise previamente levantadas durante a problematização teórica da pesquisa. Além dos encontros na escola, registramos também as reuniões de planejamento e perfis autobiográficos feitos pelas próprias convidadas, acreditando que as representações de si mesmas interferiram no aceite em participar da pesquisa, assim como na sua identificação com as personagens dos contos e na representação das crianças participantes. Estes registros estão expostos neste texto e na sua relação com as representações expostas pelas crianças, contemplamos aqui uma análise das categorias propostas no objetivo da pesquisa, com foco principal nas relações raciais.

Para tanto, organizamos o texto em duas partes, sendo que primeiramente discutimos o conceito de representação social para esta pesquisa e de que forma as narrativas autobiográficas das participantes contribuíram para nossas discussões. Neste sentido, esta primeira parte do corpo do texto também é composta por estas narrativas. A segunda parte relaciona nossas perspectivas teóricas, as narrativas das mulheres negras participantes e a análise interpretativa das representações destacadas na prática investigativa. Por fim, encaminhamos algumas conclusões da pesquisa.

\section{Contação de histórias: um convite às mulheres negras}


Compreendemos a representação social enquanto significações das estruturas sociais incorporadas pelos agentes a partir da relação entre suas disposições e (re)produzidas conforme os interesses e objetivos dos diferentes grupos e classes sociais. Conforme se dá o jogo social, algumas representações se tornam hegemônicas, atendendo aos interesses das classes e grupos dominantes quando internalizadas pelos excluídos e/ou dominados, como forma de manter a ordem social. As representações são, dessa forma, instrumentos simbólicos de reprodução da estrutura social e racial, mas que, contraditoriamente, podem ser produzidas e divulgadas como forma de enfrentar e (cor)romper o sistema excludente, promovendo relações pautadas na igualdade e na diversidade.

A partir da realidade das crianças da Escola Alcides Barcelos, para conhecer suas representações pensamos em uma metodologia que respeitasse suas posições no mundo e fosse verdadeiramente relevante para elas. Partindo do "(...) diálogo, (d) ${ }^{3}$ as expressões faciais, (d)os gestos, (d)o tom das vozes e (de) um conhecimento mútuo do tema, enfim, tudo aquilo que constitui o valor apreciativo que os interlocutores conferem ao tema do referido diálogo" (SOUZA, 2012, p. 24) convidamos mulheres negras para a contação das histórias.

Tendo por premissa a promoção de uma identidade positiva (ZIVIANI, 2012), utilizamos uma seleção de contos de autoras e personagens negros e negras, tendo como protagonistas crianças, que nos auxiliassem na estimulação de conversas com temática etnicorracial e contemplassem representações nãoexcludentes neste diálogo. Assim, decidimos pelos contos Betina, de Nilma Lino Gomes (2009), Meninas Negras, de Madu Costa (2010) e O menino Nito, de Sônia Rosa (2008).

Após a seleção dos contos, passamos a pensar nos convites para as atividades, com foco na promoção do diálogo e de representatividade sobre questões raciais com crianças pobres e negras. Sendo assim, três mulheres negras tomaram a frente das atividades, contando histórias de temática afrobrasileira e promovendo o diálogo com as crianças, de forma que se avaliassem posteriormente suas representações.

Para não expormos a identidade destas mulheres neste texto, optamos pela utilização de nomes fictícios na transcrição de seus perfis, omitindo também algumas informações pessoais. Neste texto, identificamos as convidadas pelos nomes Mariana, Dandara e Luanda (aludindo às personagens de um dos contos trabalhados (COSTA, 2010). As convidadas são mulheres negras ativistas do movimento negro e educadoras sociais e fizeram a escolha dos contos que gostariam de trabalhar a partir de suas próprias perspectivas.

${ }^{3}$ Os grifos são nossos. 
Partindo da ideia que segue o trabalho, contar histórias implicaria uma interlocução entre os/as participantes. Assim, antes de destacar as perspectivas e representações das crianças, as representações das contadoras também são relevantes na aceitação do convite e na prática das contações (e isso foi reafirmado as mesmas escolheram as histórias de maior afinidade). Desta forma, convidamos as convidadas a produzirem seu próprio perfil na participação desta pesquisa. Os textos abaixo foram produzidos pelas convidadas e contemplam informações e representações de si mesmas, assim como o motivo de terem aceitado participar desta pesquisa.

\section{Mariana - "gosto que me chamem de professora e não de tia, na sala de aula"}

Sou uma mulher negra, de origem humilde, no entanto, não me considero uma pessoa que tenha passado por situações financeiras tão precárias. Estudei em escolas públicas e privadas, tanto no Ensino Fundamental, Médio e Superior. Tive uma infância muito tranquila e muito alegre. Meu lar tinha uma excelente estrutura, havia regras, muitas regras, mas muito amor e orientação. Acredito que isso tenha influenciado muito na minha forma de viver hoje, pois adoro viver, quisera eu ter mais tempo, ter mais duas ou três vidas para fazer e viver tudo o que eu penso e gostaria. Certamente, esta vida não será o suficiente.

Escolhi sim ser professora, porque acredito que poderia ser qualquer outra coisa que quisesse, mas já na minha adolescência escolhi que seria professora e comecei a me preparar para isso. Penso que fiz a escolha certa porque adoro essa profissão, no entanto, hoje, se fosse mais jovem, escolheria outra coisa.

Esse meu envolvimento se deu desde a minha infância, quando organizei minha escolinha com apenas 8 ou 9 anos. Hoje acho incrível minha noção em organização e coordenação pedagógica. É inacreditável que com aquela idade, na "minha escolinha", eu organizava sozinha a festinha do dia das mães, me lembro até das lembrancinhas que foram compradas para oferecer para as mães dos "meus aluninhos" com o dinheiro que eu havia pedido para a festinha.

E o meu futuro, que é o meu presente agora, tornou-se como uma professora extremamente dedicada a educação, que gosta de estar sempre aprendendo, estudando sobre o máximo de coisas possíveis, aprendendo sempre com os outros, com os seus alunos. Uma realização diária, sem descanso, sem férias, diria que o tempo todo, uma mania. Acho que sou "viciada" em ser professora. Eu gosto da minha profissão e procuro atuar de maneira que me aproxime ao máximo da minha comunidade. Nunca quero ficar presa aos livros, ao que disseram, às regras. Porém, isso me causa um grande problema 
nos espaços de trabalho, pois dificilmente sou compreendida pelos colegas, pelos gestores, pelos pais, mas quando um ou outro percebe que "meu jeito" de trabalhar/ensinar nada mais é que encontrar maneiras de aprender qualquer coisa (formal ou informal; aparentemente útil ou inútil) de forma divertida, alegre, prazerosa, com amor à vida, através do autoconhecimento... Nossa! Acabo por ter legiões de fãs. Isso é interessante!

Pois bem, essa minha forma leve de querer ensinar a aprender, se posso assim dizer, que torna meu trabalho importante para as vidas que passam por mim. Acho que esse é o meu maior diferencial. Hoje, direciono meu trabalho para as questões que envolvem o povo negro na sociedade brasileira, e para mim é muito natural que se faça essa intervenção nas escolas. Pensei que minha experiência poderia alcançar outras vidas em formação, fora do meu convívio, para mitigar as suas supostas dores que julgo terem (devido à situação sócioeconômica-cultural que estão inseridas).

Ao participar dos encontros, pude perceber que infelizmente, mais uma vez não estava enganada em crer que suas infâncias Ihes foram roubadas, mas pude de alguma forma e nesse momento do encontro, recuperar um pouco disso, do seu valor como pessoa, como gente, como futuro cidadão, como crianças, como pré-adolescentes, buscando em suas memórias o desejo de viver, de se conhecer e gostar de si.

A história da Betina, que contei, a escolhi porque trazia um pouco de mim, a sua vivência com a família, principalmente a sua relação com o seu cabelo. Mesmo sendo uma história literária, trazia uma realidade que um dia foi minha, ou melhor, ainda o é, tornando esta história mais real para aquelas crianças que compartilharam aquele momento comigo e eu com elas. Por isso é um trabalho significativo, porque não cura somente os males que porventura existam nas almas das crianças que participaram, mas cura também a minha que ainda sofre por ter a cor da sua pele negra, da qual me orgulho muito.

\section{Dandara - "23 anos, mulher negra feminista e militante do movimento negro"}

Minha trajetória e descoberta do ser mulher negra, seu significado e o peso que esse marcador traz para a minha vida é algo relativamente novo, cerca de 5 anos, tempo curto se pararmos para refletir. Na verdade, quem realmente quer ser mulher e negra no Brasil? Às vezes parece ser - não posso dizer que seja fácil, porque mesmo que nós negros/as não nos identifiquemos como tal, a sociedade nos identifica - menos doloroso negar ou esconder nossa negritude. Ela agride, fere os padrões impostos pela nossa sociedade eurocêntrica e tudo 
o que está fora do padrão não é aceito, a sociedade ainda mantém resquícios da escravidão.

"Representatividade..." Essa palavra é nova para mim e para a maioria das pessoas negras. O que seria essa tal palavra? Quando eu era criança, mais precisamente quando ingressei na escola, me deparei com uma realidade totalmente diferente: colegas, professoras, personagens de livros (quando entrei para escola foi quando tive a oportunidade de ter acesso a livros, pois eram muito caros e minha mãe, empregada doméstica, e meu pai, pescador, tinham outras prioridades), todas meninas e mulheres brancas. Onde eu estava? Porque ninguém se parece comigo?

Em meio às aulas de artes e o uso dos lápis "cor de pele", a reação negativa dos meus colegas em relação aos meus traços negros, eu como qualquer outra criança me afastei de quem eu era para poder me proteger, para que doesse menos ser eu. Qual criança não gostaria de se encaixar e ser aceita como igual pelas outras?

E esse processo seguiu (e me perseguiu) até a adolescência, quando cheguei a um nível de rejeição e auto ódio no qual eu evitava pegar sol para não ficar mais preta, alisava o cabelo para tentar ser menos negra, nas rodas de discussão racial eu passava longe, pois não achava importante, quando me relacionava com alguém muitas vezes não dava certo pelo fato de eu ser negra, e assim seguiu até o momento que decidi dar um basta com tudo isso. Mulher sim, mulher e negra, preta orgulhosa e sem retroceder jamais. Mas como tudo na vida tem suas dificuldades, quando percebemos o quanto essa sociedade é racista e machista uma parte de nós volta ao passado e revive cada momento de dor que evitávamos sentir para que então possamos seguir em frente. Quando abri os olhos vi o quanto a palavra representatividade não existiu na minha infância e adolescência, eu não me via em nada que eu consumia, e doeu muito.

Quando fui convidada para participar do projeto senti como se eu voltasse ao passado sim, mas para fazer a diferença na vida das crianças. Eu, negra, estando ali conversando com eles e elas, falando sobre heroínas negras brasileiras esquecidas pela grande mídia, lendo um livro sobre meninas negras, é sim uma forma de representatividade. E é isso que falta para as crianças negras ainda nos dias de hoje, exemplos de que sim, elas podem sonhar em ser tudo o que quiserem, que acreditamos nelas, que são especiais e que elas existem.

$\mathrm{Na}$ apresentação dos contos logo de cara me apaixonei pelo livrinho chamado "Meninas Negras", o qual falava sobre três meninas e suas vidas. Vi nessas personagens minhas primas, minhas amigas, eu me vi como protagonista de algo bonito, positivo. Quando escolhi essa história foi com o intuito de levar para outras crianças esse sentimento, esse orgulho da nossa raiz 
e dizer que a nossa história não começou na escravidão, somos um povo com história e cultura e devemos ter muito orgulho da nossa ancestralidade, pois sem eles não estaríamos onde estamos e não seríamos quem somos, negras e negros.

\section{Luanda - "18 anos, sou mulher negra desde que nasci, periférica e poeta"}

Ter nascido mulher e negra, pra mim, significa ser ativista no movimento negro e no movimento feminista. A minha tomada de consciência étnica, aqui caracterizada como quando eu tive consciência do quão a escravidão deixou resquícios nessa sociedade, deu-se há uns dois anos (2014) - provavelmente em novembro - quando uma mulher negra ativista do movimento negro foi convidada a fazer um espaço para debater sobre racismo na minha antiga escola. Até aquele momento, eu não entendia o que era ser negra, para mim e para meus familiares eu era morena, mesmo sabendo que coisas me transpassavam diferentemente daquilo que atingia outras colegas brancas e magras cujo eu não entendia o porquê. Assim, como ensinada em casa, eu sustentava um discurso de que eu deveria ser forte e que aquelas(es) que não eram, eram vitimistas ou tinham um complexo de inferioridade. Toda essa base ensinada caiu por terra quando essa mulher negra ativista me disse "Talvez você não consiga ver o racismo porque é mais clarinha" e relatou agressões psicológicas e físicas que ela sofreu por ser negra. A partir desse momento, reconhecendo os meus privilégios de mulher negra de pele clara nessa sociedade racista, eu comecei a pensar e a estudar mais sobre o assunto, descobri muita coisa. Principalmente, que existiam pessoas negras por todo o mundo fazendo coisas, como por exemplo: inventando coisas, poetizando, teorizando, cantando, etc. e vou descobrindo mais com tempo, pois são muitas pessoas negras invisibilizadas de várias formas. Comecei a valorizar essas e todas as pessoas negras e seus trabalhos, visto que sempre tive pouca representatividade do povo negro na escola por conta da epistemologia, aqui caracterizada enquanto construção de conhecimento, totalmente eurocêntrica.

Essa palavra chamada representatividade é uma palavra nova, uma descoberta para mim do ano de 2016, mas eu sempre soube que isso me fazia falta. Apesar de o meu pai ser negro e sua família também, que foram com quem mais tive contato desde a minha infância, sempre estarem reverenciando sua ancestralidade através da religião ou das músicas que escutam (samba, pagode, etc.), eu sentia falta e sinto necessidade de ver pessoas negras nos espaços em que me encontro, principalmente o acadêmico (seja no que eu estudo ou nos lugares em que estou). Isso porque acredito fielmente que o ser humano se constitui enquanto ser em relação a outros seres. Nesse sentido, como construir- 
me enquanto ser mulher negra latina americana periférica, vivenciando cotidianamente costumes importados pelo capitalismo de colonizadores europeus? Por isso, tenho estudado sobre e pautado por uma educação descolonizadora, aqui caracterizada como uma educação voltada aos feitos das (os) oprimidas (os) apesar de entender o quão complicado é isso.

Assim, ter ido ler um conto sobre pessoas negras nessa escola periférica Alcides Barcelos, onde já estudei, foi uma experiência nostálgica e incrível que me inspira a continuar na licenciatura e pautar por uma educação descolonizadora. $\mathrm{O}$ contato e o debate que eu tive com aquelas crianças, desde elas brincando com as minhas calças rasgadas no joelho até os questionamentos que foram levantados na sala, foram experiências para acrescentar na minha constituição enquanto ser e espero que tenha sido recíproco. Foi e é de extrema importância que assuntos em relação à racialidade, como, por exemplo, as imposições dessa sociedade racista e sexista, que eram os temas principais do livro O Menino Nito, com o qual fizemos a leitura, sejam debatidos com crianças desde sua mais tenra idade.

\section{As representações das crianças da escola Alcides Barcelos}

"Não vai durar muito"

Considerando que as representações sociais se produzem e reproduzem nas relações entre atores e grupos sociais e que as concepções de mundo se constituem durante a infância, temos por objetivo de investigação identificar as representações de crianças pobres e negras sobre raça e pobreza, levando em conta as condições socioculturais destes grupos, sua inserção escolar e as relações sociais e raciais que se promovem neste espaço. Neste contexto, acreditamos que a pesquisa poderia ser regida na direção de compartilhar espaços e práticas conversatórias entre o grupo, assim como relacionando com a observação e análise do contexto e das relações e representações reproduzidas pelas crianças.

Desta forma, as narrativas autobiográficas transcritas acima são relevantes para a análise que segue, uma vez que a representatividade e as perspectivas de mundo das convidadas também poderiam influenciar na dinâmica da pesquisa, de abordagem qualitativa, nos auxiliando a instigar a participação destes agentes sociais, expondo seus pontos de vista, representações e experiências. Levando em conta a relevância de coleta de fontes diversificadas (OLIVEIRA, 2015), os encontros das convidadas com as crianças, ocorridos em agosto de 2016, foram coletados em áudio e vídeo e anotações no diário de campo. 
Partindo, então, da concepção de que as representações reproduzidas pela História hegemonicamente contada às crianças influenciam suas perspectivas de mundo e futuro, e privilegiando neste trabalho as concepções de agentes pobres e negros, portanto de raça e pobreza, estas foram categorias centrais que definimos para destaque, na busca de um diálogo com a revisão teórica. A análise destas categorias foi feita a partir da forma como as quais foram destacadas (ou pouco expostas) nos encontros com as crianças, relacionando-as com seu habitus, com as representações das convidadas e também com a da pesquisadora, para, por último, re(constituir) nossa compreensão das representações sociais excludentes no espaço escolar. Optamos por evitar possível identificação das crianças participantes da pesquisa. Quando citadas, portanto, trata-se de pseudônimos, assim como no caso das convidadas que contaram as histórias.

No primeiro dia em que estivemos na escola Alcides Barcelos, no início do ano letivo de 2015, conheci a estrutura do prédio, conversei com professores, funcionários e alunos. Ainda não imaginava que aquele seria o espaço retratado nesta pesquisa. Quando estava indo embora parei para conversar novamente com um grupo de alunos(as) na porta da escola, crianças e pré-adolescentes. Nesta conversa disse a todos que gostei muito da escola deles e que voltaria mais vezes. Neste momento uma das alunas riu e disse "não vai durar muito".

A frase da estudante expressa a sua compreensão das relações desenvolvidas neste espaço escolar, de acordo com o que foi observado. Professores, equipe diretiva, funcionários, colegas, projetos, não duravam muito na escola (as atividades da escola foram encerradas no segundo semestre de 2017, sendo a instituição fechada após longo processo de sucateamento ao qual foi submetida). As matrículas de muitos alunos eram instáveis devido aos seus arranjos familiares, que ora moram no bairro, ora precisam procurar outras moradias distantes. Grande parte dos professores, nomeados e contratados, ou não aceitavam trabalhar na escola e/ou no bairro, ou desistiam nos primeiros dias ou semanas, alegando que não suportavam as condições de trabalho (desde as condições físicas até as relações com os alunos, que declaram ser muito violentas, principalmente com os alunos do terceiro ciclo).

Partindo desta fala, das representações e perspectivas da aluna, apresentamos aqui a análise dos encontros registrados no último capítulo, a partir das categorias raça, pobreza, perspectivas de mundo e de futuro. As interpretações foram produzidas após o levantamento das relações e representações dos(as) estudantes nos encontros, ou seja, de suas disposições de ser, pensar e agir. Apresentamos aqui nossas interpretações sobre algumas discussões destacadas, para que possamos contextualizar as representações apresentadas pela turma. As representações mais identificadas nos encontros se referiram à categoria raça, sendo que esta era a temática central dos contos. 
No primeiro encontro com a turma, onde foi apresentado o conto "Betina" pela convidada Mariana, dos/as nove alunos/as presentes, cinco são negros/as. Quando questionados/as se brancos/as ou negros/as os/as alunos/as brancos/as não responderam, com exceção de uma menina. Cinco alunas, contudo, declararam-se negras (uma delas com hesitação), e o único aluno negro não se declarou ${ }^{4}$.

Em reunião prévia com as contadoras conversamos sobre as cores de pele e acreditávamos que os alunos/as poderiam não se reconhecer negros/as, ou os alunos/as brancos/as poderiam não os considerar negros/as. O quadro de declarações contrariou nossas perspectivas, pois não levamos em conta de que esta hipótese levantada se referia a uma realidade específica, diferente daquela vivida pelos/as alunos/as da escola Alcides Barcelos, que eram, em maioria na sala, negros e negras, num bairro majoritariamente negro.

\section{Na verdade, quem realmente quer ser mulher e negra no Brasil?}

Pensando nas discussões das reuniões de planejamento, acreditamos num primeiro momento que estudantes classificariam a raça dos/as colegas a partir de critérios de "desvalorização sistemática dos atributos do sujeito negro" (SOUZA, 1983, p.5-6). Souza, analisando os depoimentos e representações de sujeitos negros, relata que há desprezo e estigmatização das características físicas das pessoas negras (SOUZA, 1983, p.6). Compreendendo estas representações como excludentes e hegemônicas, tivemos por hipótese que os/as alunos/as, negros/as ou brancos/as, classificariam a si mesmos e aos colegas, desqualificando a identidade dos/as) negros/as que não atendessem a um "conjunto de critérios". De fato, aplicamos uma pontuação às representações excludentes dos/as alunos/as sem antes ouvi-los, o que nos fez contrariar as perspectivas teóricas.

Os alunos Ana e Carlos, durante os encontros, de diferentes formas mostraram-se incomodados com a temática, em função de repercutir neles enquanto alvos dos colegas. Ele simplesmente não nos respondia quando perguntávamos se era branco ou negro, se gostava dos contos, a raça dos/as personagens dos contos que lia na biblioteca da escola, se já aprendera sobre a África na escola ou fora dela, etc., nos mirando fixamente ou rindo, o que não ocorria quando fugíamos à temática racial. Ela respondia dizendo que não sabia, não queria participar, dando com os ombros, debochando ou sugerindo que os/as outros/as colegas respondessem. Mas ambos se negaram parecer com os/as personagens dos contos. Estes comportamentos nos remeteram às

\footnotetext{
${ }^{4}$ Enquanto classificação fenotípica feita pela pesquisadora.
} 
discussões para a identidade etnicorracial e ao relato da contadora Dandara no seu perfil, que questiona: "Na verdade quem realmente quer ser mulher e negra no Brasil?". Neste mesmo sentido, por que uma criança negra vai querer se reconhecer enquanto tal, quando esta identidade é vista como algo ruim e feio (ZIVIANI, 2012)? No texto da contadora Dandara também há relatos das formas de defesa que incorporava "para que doesse menos" ser ela mesma, que chegou num "nível de rejeição e auto-ódio" que vigiava seu corpo e evitava rodas de discussão racial para rejeitar a temática.

Assim, acreditamos que os alunos Ana e Carlos, principais alvos da violência racial dos/as colegas, reagiam negativando a temática, como forma de não assumir a representação de um "sujeito negro" para si, como que tentando fazer sua identidade desaparecer. Para Souza (1983) a identidade dos sujeitos negros desaparece em subordinação ao ideal de um sujeito universal branco, antagônico em "[...] relação à identidade de seu corpo e de sua história étnica e pessoal" (SOUZA, 1983, p.5). A legitimação do sistema escravista passou por um processo de desumanização do negro e o mesmo foi reinventado durante 0 século XX para manter a exclusão social e racial. O racismo foi reproduzido de uma forma que os/as próprios/as negros e negras assimilem representações excludentes de si (mas produzidas pela branquitude) e tomem as mesmas enquanto verdade, endossando a desigualdade racial (FERNANDES, 2007, p.28-29).

Por fim, cabe pensar no diálogo travado entre três alunas, que desencadeou a fala que nomeia este subtítulo. Conversando com a colega Ana sobre os imigrantes africanos que trabalham como ambulantes no centro da cidade, Luciana acusou-a de racismo pelo que disse (que não tivemos conhecimento, visto que foi dito em cochichos), e enquanto Ana fazia uma expressão de espanto e questionamento pela acusação, uma terceira colega questionou, apontando pra mesma: "Como ela vai ser racista?". Esta última fala nos fez interpretar que ela estava se referindo a raça/cor da colega, que a impediria de ser racista. Dentre as outras falas, esta destacou a noção da aluna de que a colega, por ser negra é vítima de racismo e não praticante. De fato, como temos visto, as crianças reproduzem as representações que interiorizam nas instituições sociais. Dessa forma, seria possível a prática racista da menina negra, visto que está em posição desprivilegiada na sociedade brasileira?

Segundo Moore (2007, p.211) "o racismo beneficia e privilegia os interesses exclusivos da raça dominante, prejudicando somente os interesses da raça subalternizada. O racista usufrui de privilégios e do poder total enquanto o alvo do racismo experimenta exatamente a experiência contrária". Dessa forma, só existe racismo por parte do racista. Este mesmo autor contribui para a nossa compreensão sobre a identificação e classificação de raça das crianças. Conforme Moore (2007, p.11) "O fenótipo é um elemento objetivo, real, que não se presta à negação ou confusão. É o fenótipo que serve de linha de demarcação 
entre os grupos raciais, e como ponto de referência em torno do qual se organizam as discriminações 'raciais'”. A identificação de raça das crianças parte, portanto, das características fenotípicas. Ou seja, como dito pela convidada Dandara, mesmo que as crianças não quisessem se identificar, a sociedade Ihes identifica. Isso também pode ser identificado no relato da convidada Luanda, quando a mesma diz que é mulher negra "desde que nasceu", mesmo que não tenha se identificado dessa forma por bastante tempo.

Isso, por um lado, nos fez surpreender quando no primeiro encontro todas as meninas negras presentes se identificassem enquanto tal, independentemente de suas tonalidades de pele - como teríamos acreditado nos encontros de programação das atividades. Por outro, a aluna com a cor de pele mais escura da sala fora, em todos os encontros, alvo de racismo e olhares de questionamento, que a pressionavam a participar oralmente das atividades como se a temática racial interessasse apenas a ela mesma. O mesmo ocorreu com o único menino negro da turma, em especial no último encontro, quando o personagem principal do conto também era um garoto negro.

Elencamos também situações dos encontros em que se destacaram representações sobre pobreza (enquanto desvantagem material e imaterial) e as perspectivas de mundo e futuro das crianças. Devido a maior intensidade das discussões sobre raça nas atividades, em função da temática principal dos contos, estas categorias de estudo foram percebidas em menor número e, sendo dessa forma, decidimos por relacioná-las no texto.

Nos questionamos se o fato das categorias de análise terem sido pouco identificadas não nos diz também sobre as reações dos/as alunos/as? Pensamos que isto pode ter ocorrido porque as representações dos/as personagens não contemplavam as perspectivas dos/as alunos/as - ora, meninas negras estudando a diversidade e ancestralidade africana na escola e tornando-se profissionais que apresentam palestras nestas mesmas instituições (contos Betina e Meninas Negras)? Um menino negro que tem sua sensibilidade representada e não estereotipado enquanto agressivo e desobediente? Não são estas as representações que regulam as relações destes grupos sociais, tanto que, no que toca a representação de mulheres negras reais durante as atividades, as alunas participantes foram surpreendidas. Desta forma, acreditamos que o fato de os contos representarem algo que é fantasioso para os/as alunos/as pode ter interferido também na exposição de suas representações.

Isto posto, destacamos a relação entre raça e gênero nas disposições das alunas (enquanto perspectivas de mundo e futuro), no que se refere ao seu desperto interesse pelas convidadas, autoras e ilustradoras negras. No primeiro encontro com a convidada Mariana, convidamos a turma a conferir quem seriam as autoras e atentamos para o fato de serem negras. Nos dois próximos 
encontros as meninas pediam desde o início da atividade para ver as fotografias e informações sobre as autoras e ilustradoras(es) constantes no final do livro.

Ainda, no segundo encontro, a contadora Dandara (partindo também de suas perspectivas de mundo), iniciou uma conversa com as alunas sobre heróis e heroínas, explicando que as mulheres são negligenciadas na história do Brasil. Dentre os/as cinco alunos/as que participavam da atividade, três meninas permaneceram atentas ao que a contadora dizia. Então a mesma apresentou às alunas as "suas heroínas", Dandara dos Palmares ${ }^{5}$ e Tereza de Benguela6, contando suas histórias e circulando seus retratos. A aluna Ana, que até o momento parecia negligenciar as falas da contadora, diferente do primeiro encontro em que negou ser parecida com a personagem, sorrindo pareceu muito satisfeita quando apontada a sua semelhança com a líder quilombola Tereza de Benguela, a todo momento colocando o retrato da heroína ao lado do seu rosto, comparando-se a ela e sorrindo.

Destes comportamentos das meninas em relação às autoras, ilustradoras, heroínas e contadoras nos remetemos aquilo que Ziviani (2012) chama de identidade positiva. Estas alunas, em maioria negras, parecem ter mostrado devido interesse por estas mulheres, visto que identificaram-se com as mesmas quando perguntavam sobre elas, pedindo para ver suas fotos e pedindo informações sobre suas vidas. Acreditamos que estas personagens "reais" representam para as alunas outras perspectivas de si e da população negra, que não aquela contada na Escola, mas a reivindicada pelas convidadas quando questionavam "Quem aqui se parece comigo?" (Dandara) e a importância de pessoas negras ocuparem espaços de poder. Mesmo que estas representações estejam intimamente relacionadas à categoria raça, optamos por apontá-las aqui por também dizerem respeito às perspectivas de mundo e futuro das meninas negras ao terem exemplos reais de mulheres negras numa posição que não é de servidão ou subalternização. Isso também se relaciona à representação da contadora Dandara da população negra brasileira enquanto grupo, seja no seu perfil, seja quando se localizava na história e no mundo: "a história do negro começou na África, lá a gente não era escravo”.

Por outro lado, o aluno Carlos não demonstrou a mesma satisfação quando relacionado ao personagem Nito, visto que a relação desencadeou mais

\footnotetext{
5 "Guerreira do período colonial do Brasil, Dandara foi esposa de Zumbi, líder daquele que foi o maior quilombo das Américas: o Quilombo dos Palmares. [...] Foi uma das lideranças femininas negras que lutou contra o sistema escravocrata do século XVII e auxiliou Zumbi quanto às estratégias /e planos de ataque e defesa do quilombo". Disponível em http://www.palmares.gov.br/?p=33387.

6 'Teresa de Benguela foi uma líder do quilombo de Quariterê, no Mato Grosso, não se sabe se africana ou brasileira. Dizem que liderou um levante de negros e índios, instalando-se próximo a Cuiabá, não muito longe da fronteira com a atual Bolívia. Durante décadas, Teresa esteve à frente do quilombo, o qual sobreviveu até 1770 , século XVIII". Disponível em http://www.mulher500.org.br/destaques-conteudo.asp?cod=26.
}

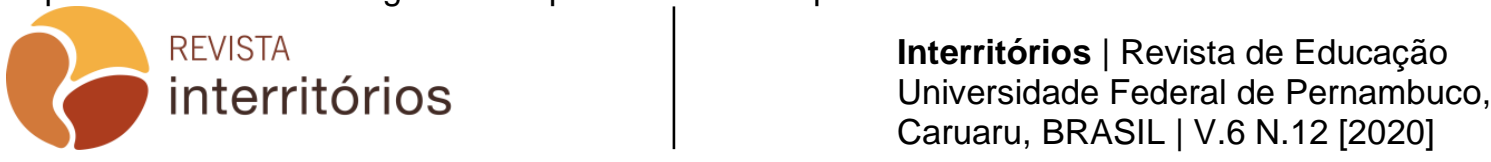


uma vez sua condição de alvo dos outros meninos, brancos, chamando-o pejorativamente de "chorão" e de "guria". Ou seja, mesmo que tenhamos tentado abordar a discussão racial a partir de um conto em que o personagem, diferente dos anteriores, é um garoto (esperando contemplar outros agentes), isto fez com que a violência racial dos/as colegas se exacerbasse sobre o aluno. Quando meninos negros são estigmatizados como agressivos, brutos, insensíveis e desobedientes, ou seja, animalizados (e isso por si só configura uma violência), não corresponder a essas representações parece que também forja um motivo para pessoas brancas praticarem racismo, visto que o agente não atende às suas perspectivas de raça e masculinidade.

No final do primeiro encontro, a contadora Mariana questionou aos/às alunos/as sobre o futuro da personagem Betina. Dentre os/as colegas, acompanhando atentamente o desfecho da história, a aluna respondeu: "Mãe?' (mais tarde, durante o intervalo da escola a aluna disse que planeja ser mãe durante a adolescência). A contadora explicou que se referia a uma profissão e que Betina teria se tornado uma cabeleireira famosa, que ensinava as pessoas a gostarem de tranças e amarem a si mesmas enquanto negras. Este momento desestabilizou nossas representações de que evidentemente a pergunta da contadora dizia respeito à profissão da personagem, quando, na verdade, eram as representações da aluna (também sobre seu futuro e trajetória pessoal) que estavam sendo expostas. Ao final do segundo encontro, contudo, após os contos Betina e Meninas Negras e as conversas da convidada Dandara sobre heroínas negras, a aluna disse desejar ser policial. Afinal, teria ela desvinculado a noção do seu futuro à maternidade, cogitado outra alternativa no seu horizonte de expectativas que envolvesse uma posição de autoridade, ou apenas expressou outro interesse? Não é do interesse deste trabalho analisar papéis individuais, pois não é possível saber o que a fez mudar - ou se mudou - sua perspectiva/narrativa entre o primeiro e o segundo encontro. Contudo, é relevante pensar que pode ter influenciado suas perspectivas de futuro.

Tanto quanto expressões das estruturas raciais e sociais, percebemos as representações reproduzidas ou reformuladas nas experiências individuais, como um retrato do grupo. Dessa forma, quando percebemos uma (re)ação variada entre a contadora Mariana, que escolhe o conto Betina por ter sua identidade valorizada e representada pela personagem e pela trama da história, e a aluna que nega sua semelhança com a mesma, percebemos que as categorias raça e gênero (esta última aqui brevemente exposta) e suas representações repercutem sobre elas de forma que a primeira busca superar a violência racial e a segunda tenta defender-se da mesma, quando ambas são alvo de violência. Assim, percebemos que, mesmo que predominem representações historicamente excludentes, há possibilidade de refazer a educação etnicorracial a partir de representações que valorizem e respeitem a 
história da população negra brasileira (como as expostas pelos contos e contadoras).

Este mesmo entendimento tivemos quando, no segundo encontro, após a contadora Dandara definir as mulheres negras historicamente invisibilizadas Tereza de Benguela e Dandara dos Palmares como "suas heroínas", recebeu em troca a simpatia da aluna, também negra, que, colocando ao lado do seu rosto a figura de uma das heroínas, sorrindo mostrava às colegas ser, de fato, parecida com aquela personagem, que, diferente da ilustrada no conto Betina, existiu e resistiu no Brasil escravocrata, como exposto pela contadora.

Ao final deste encontro a convidada Dandara, referindo-se a forma que a aluna Ana é (mal)tratada pelos/as colegas, disse que sabe como "é difícil ser a única menina negra da turma". A estudante relatou um pouco disso também no seu perfil e demonstrou o seu desejo em auxiliar as crianças na busca de uma identidade positiva, de um "gostar de si" querendo mostrar a eles que a história de negros e negras é "uma história que não começa na escravidão".

É desta forma que, acreditamos, os contos, podem contribuir na (re)produção de representações antirracistas nas instituições escolares. Introduzindo, de forma lúdica, a temática de uma história que contesta aquela hegemonicamente contada, e que aborda com respeito e posicionamento antirracista, a história de negros e negras que viveram e vivem no Brasil, suas condições, lutas, conquistas e direitos. Como representado na escrita da contadora Luanda, existem muitas "pessoas negras por todo o mundo fazendo coisas, como por exemplo: inventando coisas, poetizando, teorizando, cantando etc."

As justificativas das contadoras na participação da pesquisa - a relevância para si de contribuir na construção de uma sociedade antirracista na busca de uma representatividade negra, os seus posicionamentos, as relações respeitosas com as crianças e suas percepções do espaço escolar, demonstram a resistência possível frente à estrutura e a história hegemônicas. A atuação das convidadas nos espaços que constroem, suas perspectivas de mundo e representações foram especiais no contato com as crianças, como almejávamos.

A representatividade das pessoas negras também foi reivindicada neste outro sentido por atores desta pesquisa: no direito a pertencer aos espaços sociais. Isto está representado no interesse dos/as alunos/as pelas autoras e ilustradores/as negros/as, das meninas pelas heroínas negras, e nas falas das convidadas que relatam suas experiências em espaços predominantemente brancos e a relação que há entre isso e o poder.

Mesmo que não fosse esta a intenção inicial deste trabalho de pesquisa, fomos construindo seu trajeto de tal forma referente a representações 
antirracistas, que acabamos por realçar esta temática. De forma alguma deixamos esquecer a relação entre as estruturas raciais e sociais, o que foi bem exposto no contexto histórico e nas condições dos atores participantes da pesquisa, mas como reivindicado na fala de algumas convidadas, foi importante salientar as representações e valorização da população negra.

\section{CONCLUSÃO}

As contadoras Dandara e Luanda expuseram nos seus relatos que a escola foi uma das instituições que as reprimiram e excluíram enquanto meninas negras. Foi negada a sua cor e sua história, como forma de perpetuar a exclusão social e racial. Além disso, em todos os perfis, se confirmou nossa concepção de que as perspectivas de mundo dos/as agentes sociais são incorporadas durante a infância: em todos os perfis as convidadas retornam à infância para justificar suas vidas.

Esta percepção foi muito relevante para o andamento da pesquisa, visto que nossa noção de representação social e racial, assim como os gatilhos para a exposição das representações dos/as alunos/as, dependeram da participação das convidadas nas atividades e planejamentos. Os perfis das convidadas, também se relacionam com as perspectivas e representações das crianças da Alcides Barcelos. Isso pode ser percebido nas suas escritas quando a convidada Mariana se apresenta, autodeterminando sua autoridade enquanto profissional e refazendo o seu exercício constante de provar ser capaz quando diz que "poderia ser qualquer outra coisa que quisesse"; e na preocupação da Dandara e da Luanda com que as crianças tenham exemplos de que "podem sonhar em ser tudo o que quiserem", como muitas outras pessoas negras.

Como pretendíamos no princípio desta pesquisa, sustentamos nossa perspectiva de que o racismo, enquanto violência racial institucionalizada no Brasil também através da reprodução de representações excludentes, interfere nas perspectivas e condições de vida dos atores sociais. Em sala de aula, percebemos que num grupo majoritariamente negro, crianças negras escondiam-se da temática racial, enquanto crianças brancas faziam valer 0 privilégio da brancura, através da violência, da humilhação e do sentimento exposto de superioridade racial.

Contudo, acima destas relações de poder que se engendram no espaço escolar estão os sistemas de ensino que mantém sua reprodução. Ao analisar as representações sociais e a exclusão social a partir de um recorte racial, concluímos que relações de força constituintes da sociedade brasileira estão postas nas escolas (e, portanto, no ensino de História), instituições que atendem em massa crianças e jovens pobres e negras, no sentido de reproduzir a estrutura social excludente. A partir das representações das crianças, vimos que 
suas disposições de ser, agir e pensar estão submetidas à arbitrariedade da escola, à vulnerabilidade das condições de vida das crianças e à herança familiar, perpetuando ciclos de pobreza e desigualdade que, quando analisados com recorte racial, prejudicam com maior intensidade meninos e meninas negras.

Nestas condições e pensando a exclusão social e analisando a discussão de raça, foi possível perceber que quando os estudantes negam as histórias de sofrimento, recebem este tema com represália, significa não quererem identificar-se, por resistência. Assim, sob a deterioração da imagem do negro, apreendida pela vítima, reforçada pela sociedade brasileira, forjam-se maneiras de resistir à discriminação, onde a negação de sua negritude pode ser uma delas. Sendo o discurso hegemônico de desvalorização etnicorracial e culpabilização das condições de exclusão, os grupos oprimidos introjetam estas representações, negando sua identidade, por entendê-la enquanto desvantagem.

Por fim, salientamos nossa preocupação e compromisso na construção de uma sociedade antirracista. Entendemos que é possível nadar contra a corrente de práticas e representações sociais desiguais (e que se não houvesse tal expectativa, essa pesquisa se classificaria num grande vazio intelectual); vimos isto nas palavras de todos os autores e autoras selecionados para nosso aporte teórico e metodológico, nos relatos e práticas das mulheres negras convidadas a contar histórias e compartilhar as suas próprias, no interesse das pessoas que auxiliaram para que as práticas e coletas investigativas fossem possíveis, na banca de qualificação composta por mulheres negras coordenadoras de núcleos de estudos afro-brasileiros, na aceitação e cooperação da equipe escolar para que tratássemos tais temas em suas salas de aula e, especialmente, no impacto positivo que esperamos ter causado nas crianças que dispuseram suas perspectivas e representações à arrogância acadêmica.

Nossas práticas foram pensadas neste sentido. Entre as várias formas de ensinar história para crianças, acreditamos que o modelo que utilizamos nas investigações possa promover uma reeducação etnicorracial no espaço escolar (sem a pretensão de uma transformação social, mas de impactar as relações, representações e perspectivas de crianças pobres e negras). Lançamos, assim, este trabalho como uma contribuição inacabada, mas que introduz possibilidades de pensar a introdução da História ainda nos anos iniciais com vistas à igualdade racial.

\section{REFERÊNCIAS}


AGUIRRE, Kathleen Kate Dominguez Aguirre. Entre a História ensinada e a reprodução de representações excludentes. Dissertação (mestrado). Programa de Pós Graduação em História, Universidade Federal do Rio Grande - FURG. Rio Grande, RS, 2017.

BOURDIEU, Pierre. CHAMPAGNE, P. Os excluídos do interior. In.: BOURDIEU, Pierre. A miséria do mundo. Petrópolis, RJ: Vozes, 2012.

BOURDIEU, Pierre. O poder simbólico. Rio de Janeiro: Bertrand Brasil, 2012.

BOURDIEU, Pierre.; \& CHARTIER, Roger. O sociólogo e o historiador. Belo Horizonte: Editora Autêntica, 2011.

CARDOSO, Lourenço. Branquitude acrítica e crítica: a supremacia racial e o branco antiracista. In.: Revista Latinoamericana de Ciencias Sociales, Niñes e Juventud (Vol. 8 n. 1. Ene-Jun 2010. Disponível em

http://biblioteca.clacso.edu.ar/Colombia/alianza-cinde-

umz/20131216065611/art.LourencoCardoso.pdf. Acesso em: 20 jul 2020.

CHARTIER, Roger. Historia intelectual e historia de las mentalidades. Trayectoria y preguntas. In.: CHARTIER, Roger. El mundo como representación. Estudios sobre historia cultural. Barcelona: Gedisa Editorial, 2009.

COSTA, Madu. Meninas Negras. Belo Horizonte, Mazza Edições, 2010.

FERNANDES, Florestan. O negro no mundo dos brancos. São Paulo: Global, 2007.

GOMES, Nilma Lino. Betina. Belo Horizonte: Mazza Edições, 2009.

MOORE, Carlos Wedderburn. 0 racismo através da história: da antiguidade à modernidade. Salvador: Instituto Cultural Steve Biko, 2007.

MUNANGA, Kabengele. Superando o Racismo na escola. Brasília: Ministério da Educação, Secretaria da Educação Continuada, Alfabetização e Diversidade, 2005.

PINHEIRO, Adevanir Aparecida. O espelho quebrado da branquidade: aspectos de um debate intelectual, acadêmico e militante. São Leopoldo, Casa Leira, 2014.

ROSA, Sonia. O menino Nito. Rio de Janeiro: Pallas, 2008.

SCHUCMAN, Lia Vainer. Sim, nós somos racistas: estudo psicossocial da branquitude paulistana. In.: Psicologia e Sociedade, 26, 83-94. 2014. Disponível em http://www.scielo.br/pdf/psoc/v26n1/10.pdf. Acesso em 20 jul 2020.

SILVA, Petronilha Beatriz Gonçalves e. Aprender, ensinar e relações étnico-raciais. In.: Educação, Porto Alegre/RS, ano 2007, n.3 (63), P.489-506. Disponível em: http://revistaseletronicas.pucrs.br/ojs/index.php/faced/article/download/2745/2092 .

SOUZA, Neusa Santos. Tornar-se negro: as vicissitudes da identidade do negro em ascensão social. Rio de Janeiro: Edições Graal, 1983.

SOUZA, Solange Gigin Roeles de. Ensino de História e cultura afrobrasileira e africana através dos contos africanos. Monografia (Especialização) - Pós 
Graduação em Educação: Métodos e Técnicas de Ensino, Modalidade de Ensino a Distância, da Universidade Tecnológica Federal do Paraná, 2012.

ZIVIANI, Denise. A cor das palavras: a alfabetização de crianças negras entre os estigmas e a transformação. Belo Horizonte: Mazza Edições, 2012. 256 p. 